\title{
Processing Effects on Fracture Toughness of Metallic Glasses
}

Wen Chen ${ }^{\text {a }}$, Haofei Zhou ${ }^{\text {b }}$ Ze Liu ${ }^{\text {a, c }}$, Jittisa Ketkaew ${ }^{\text {a }}$, Ning Li ${ }^{\text {a, }}$ James Yurko ${ }^{\text {d }}$, Nicholas Hutchinson ${ }^{\mathrm{d}}$, Huajian Gao ${ }^{\mathrm{b}}$, Jan Schroers ${ }^{\mathrm{a}, \mathrm{e}^{*}}$

${ }^{a}$ Department of Mechanical Engineering \& Materials Science, Yale University, New Haven, CT, 06511, USA

${ }^{\mathrm{b}}$ School of Engineering, Brown University, RI, 02912, USA

${ }^{\mathrm{c}}$ Department of Engineering mechanics, School of Civil Engineering, Wuhan University, Wuhan, 430000, China

${ }^{\mathrm{d}}$ Materion Corporation, Mayfield Heights, $\mathrm{OH}, 44124$, USA

${ }^{\mathrm{e}}$ Center for Research on Interface Structures and Phenomena (CRISP), Yale University

* Corresponding author. Tel.: +1 203432 4346; fax: +1 2034326775 .

Email address: jan.schroers@yale.edu (J. Schroers) 


\begin{abstract}
Measuring fracture toughness of metallic glasses (MGs) is challenging, and a large scatter has been observed which has been at least partially attributed to varying processing conditions. Here, we investigated the influence of main processing conditions, cooling rate and processing environment, on the fracture toughness of MGs. Through a thermoplastic forming based toughness evaluation approach, we found that processing effects can be dramatic and typically very specific to the alloy. Hence, general predictions of processing effects are challenging and MG specific characterization are required; however we offer some insight how the cooling rate effect can be explained with fictive temperatures.
\end{abstract}

Keywords: metallic glass; toughness; impurity embrittlement; fictive temperature 
Structural materials are often limited by fracture toughness rather than strength [1]. Mechanistically, fracture resistance of a material is controlled through its deformation mechanism that is governed and mediated by the material's specific microstructures. For crystalline metals, the fracture behavior has been extensively studied and has been linked to a variety of constituting microstructural features such as dislocations, grain boundaries, and secondary phases, which often provides a microscopic basis for quantitatively understanding their fracture mechanisms [2]. This is not the case for metallic glasses (MGs). MGs are amorphous metals that are vitrified during cooling the melts. The amorphous feature of MGs endows them with a myriad of unusual properties including high strength and high elasticity $(\sim 2 \%)$, paired with unique thermoplastic formability in the supercooled liquid state [3-8]. The lack of ordered crystalline microstructure in MGs makes the conventional concept of "microstructure-property" relationships futile and poses a challenge in mechanistically linking their fracture behavior to the microstructure.

For crystalline materials, processing often plays a crucial role in determining the fracture toughness and the resulting effect is at least for some aspects reasonably well understood through the abovementioned material's microstructural features. A variation in processing conditions (e.g., cooling rate) of crystalline materials leads to different constituent phases and grain sizes, microstructural morphologies, volume fractions, and hence different fracture toughness values [9-11]. For MGs, processing has also been suggested as a key contributor to the fracture toughness determination [12-14]. For example, a significant toughness variation ranging from 16 to $\sim 130 \mathrm{MPa} \sqrt{\mathrm{m}}$ has been recorded for $\mathrm{Zr}_{41.2} \mathrm{Ti}_{12.5} \mathrm{Cu}_{10} \mathrm{Ni}_{10} \mathrm{Be}_{22.5}$ that were prepared at different conditions [15-19]. However, due to the absence of well-defined microstructures in MGs, the underlying mechanism for the effect of processing on the fracture toughness remains 
mysterious. Most common example is the cooling rate, which affects the fictive temperature of a MG through "selecting" one of the vast number of possible structural states on the potential energy landscape [20]. However, how these different metastable states mechanically behave is, besides some general concepts [21], not yet well understood.

In this work, the effect of processing on the fracture toughness of representative MGs has been systematically studied through a thermoplastic forming (TPF) based toughness evaluation approach combined with Si photolithography. The high precision, reproducibility, and versatility in test sample control of our method allow independent and precise control of the processing conditions that has being difficult for conventional casting based toughness sample preparation $[22,23]$. Specifically, we individually manipulate most critical processing conditions, namely cooling rate and chemical impurities, and independently investigate their influence on the toughness variation of MGs. Our study reveals that processing effect on fracture toughness of MGs can be significant yet typically alloy-specific.

Two representative MGs, $\mathrm{Zr}_{44} \mathrm{Ti}_{11} \mathrm{Ni}_{10} \mathrm{Cu}_{10} \mathrm{Be}_{25}$ and $\mathrm{Pd}_{43} \mathrm{Cu}_{27} \mathrm{Ni}_{10} \mathrm{P}_{20}$, were used, which exhibit distinct mechanical behaviors, reflected in their difference in critical fictive temperature with respect to their calorimetric glass transition temperature [21]. Master alloy ingots of $\mathrm{Zr}_{44} \mathrm{Ti}_{11} \mathrm{Ni}_{10} \mathrm{Cu}_{10} \mathrm{Be}_{25}$ and $\mathrm{Pd}_{43} \mathrm{Cu}_{27} \mathrm{Ni}_{10} \mathrm{P}_{20}$ were prepared by arc-melting a mixture of the pure elements in an argon atmosphere. The amorphous state was achieved by water quenching into a 5 $\times 100 \times 140 \mathrm{~mm}^{3} \mathrm{Cu}$ mold. The amorphous nature of the MGs was both confirmed by X-ray diffraction (XRD) and differential scanning calorimeter (DSC). The onset glass transition temperature, $T_{g}$, and crystallization temperature, $T_{x}$, for $\mathrm{Zr}_{44} \mathrm{Ti}_{11} \mathrm{Ni}_{10} \mathrm{Cu}_{10} \mathrm{Be}_{25}$ are $616 \mathrm{~K}$ and 751 $K$, respectively, while $T_{g}=578 K, \quad T_{x}=669 K$, for $\mathrm{Pd}_{43} \mathrm{Cu}_{27} \mathrm{Ni}_{10} \mathrm{P}_{20}$ are measured, both at a standard heating rate of $20 \mathrm{~K} / \mathrm{min}$ by DSC. Single edge notched tension (SENT) sample 
geometry was designed to measure the notch toughness, $K_{Q}$. A notch with radius of $\rho \approx 150 \mu \mathrm{m}$ was precisely introduced from the central edge of the sample, and a pair of two holes was designed in each end of the sample to facilitate alignment during uniaxial tension tests (Fig. 1). A general Si photolithography technique was employed to fabricate the molds with an etching depth of $\sim 0.35 \mathrm{~mm} . \mathrm{Zr}_{44} \mathrm{Ti}_{11} \mathrm{Cu}_{10} \mathrm{Ni}_{10} \mathrm{Be}_{25}$ and $\mathrm{Pd}_{43} \mathrm{Cu}_{27} \mathrm{Ni}_{10} \mathrm{P}_{20}$ were formed into Si molds by TPF molding at $700 K$ and $630 K$, respectively under a pressure of $20 \mathrm{MPa}$ for 100 seconds and subsequently quenched. Fracture toughness tests were conducted on an Instron machine under a quasi-static displacement-controlled mode (strain rate: $\left.10^{-4} \mathrm{~s}^{-1}\right)$. To correlate the stress-strain $(\sigma$ $\varepsilon)$ curves with the notch propagation and plastic zone development, in-situ deformation images were recorded by a Qimaging Go-5 CCD camera. This allows for capturing the plastic zone size developed prior to fracture, $R_{p}$. The stress intensity factor $K$ for the SENT geometry can be calculated through $K=\sigma \sqrt{\pi a} F\left(\frac{a}{W}\right)$, where $F\left(\frac{a}{W}\right)$ is a configuration correction factor [24]

$$
F\left(\frac{a}{W}\right)=\sqrt{\frac{2 W}{\pi a} \tan \frac{\pi a}{2 W}} \cdot \frac{0.752+2.02\left(\frac{a}{W}\right)+0.37\left(1-\sin \frac{\pi a}{2 W}\right)^{3}}{\cos \frac{\pi a}{2 W}}
$$

with $\sigma$ is the fracture strength of the notched sample, $a$ is the notch crack length, and $W$ is the sample width. Through our approach based on Si photolithography and TPF, sample fabrication precision of $\sim 1 \mu \mathrm{m}$ can be achieved, which gives rise to a high reproducibility. For example, only 3\% scatter was measured among $20 \mathrm{Zr}_{44} \mathrm{Ti}_{11} \mathrm{Cu}_{10} \mathrm{Ni}_{10} \mathrm{Be}_{25}$ SENT samples under highly controlled and identical processing conditions, material compositions, and geometries [22]. It should be noted that the notch here is relatively blunt and the sample thickness is relatively thin, which may result in errors in approximating the absolute value of the toughness. Therefore, we call the toughness value measured here as notch toughness $\left(K_{Q}\right)$ approximated by Eq. (1). The focus of this work is to identify the processing effects on toughness of MGs by mitigating 
previously reported extrinsic contributions, and this can be achieved most efficiently for thin samples.

It has been widely observed that cooling rate is a major processing parameter that can significantly affect MGs' properties [21, 25, 26]. In order to investigate the influence of cooling rate on the fracture toughness of MGs, two different cooling rates, air cooling $(\sim 5 \mathrm{~K} / \mathrm{s})$ and water cooling ( $\sim 50 \mathrm{~K} / \mathrm{s})$, were employed for both considered MGs. Processing was carried out that the MGs were thermoplastically formed into the precise dimensions of the test geometry and subsequently cooled at the different rates to room temperature. Considered cooling rates are higher than the critical cooling rates of $\sim 0.1 \mathrm{~K} / \mathrm{s}$ and $\sim 1 \mathrm{~K} / \mathrm{s}$ for glass formation of $\mathrm{Pd}_{43} \mathrm{Cu}_{27} \mathrm{Ni}_{10} \mathrm{P}_{20}$ and $\mathrm{Zr}_{44} \mathrm{Ti}_{11} \mathrm{Cu}_{10} \mathrm{Ni}_{10} \mathrm{Be}_{25}$, respectively, to ensure the amorphous structure [2730] and to avoid any possible crystallization which may affect fracture toughness [31]. We found that $K_{Q}$ of $\mathrm{Pd}_{43} \mathrm{Cu}_{27} \mathrm{Ni}_{10} \mathrm{P}_{20}$ decreases from $\sim 76 \mathrm{MPa} \sqrt{\mathrm{m}}$ for the water-cooled condition to $\sim 43$ $\mathrm{MPa} \sqrt{\mathrm{m}}$ for the air-cooled condition. The corresponding $R_{p}$ decreases from $\sim 255 \mu \mathrm{m}$ to $\sim 30$ $\mu \mathrm{m}$ (Fig. 2a and 2b). In contrast, $K_{Q}$ and $R_{p}$ of $\mathrm{Zr}_{44} \mathrm{Ti}_{11} \mathrm{Cu}_{10} \mathrm{Ni}_{10} \mathrm{Be}_{25}$ are essentially unaffected by considered cooling rate variation (Fig. 2c and 2d).

We hypothesize that the observed differences in the cooling rate sensitivity of MGs' mechanical behavior can be rationalized based on a phenomenological concept of "fictive temperature" $\left(T_{f}\right)$ [21]. For a given MG, different cooling rates result in different glassy states on the potential energy landscape and a higher cooling rate results in a higher potential energy and a higher fictive temperature, $T_{f}$ (Fig. $2 \mathrm{e}$ and 2f) [20]. Practically, varying cooling rates in the experimentally accessible region to form bulk metallic glasses lead to a variation of $T_{f}$ in the range of $\sim 40 \mathrm{~K}$ for most MGs [21]. For a given MG, there exists a critical cooling rate yielding its critical characteristic fictive temperature, $T_{f c}$. If the applied cooling rate is higher than the 
critical cooling rate, the resulting glassy state of the MG tends to be tough and vice versa. Within this fictive temperature framework, all MGs can be categorized into two groups: $T_{f}\left\langle T_{f c}\right.$ and $\left.T_{f}\right\rangle$ $T_{f c}$. For the former group, the critical cooling rate for embrittlement is higher than that for glass formation. The magnitude of $T_{f}-T_{f c}$ determines their mechanical properties and their sensitivity to the cooling rate. MGs with $T_{f}$ slightly smaller than $T_{f c}$ should be sensitive to varying cooling rates and can exhibit a brittle-to-ductile transition if variation in $T_{f}$ is caused (by increasing the cooling rate) in the experimentally accessible region to exceed $T_{f c}$, as represented in the case of $\mathrm{Pd}_{43} \mathrm{Cu}_{27} \mathrm{Ni}_{10} \mathrm{P}_{20}$, where its critical fictive temperature, $T_{f c(P d)}$, is in the vicinity of its $T_{f}$, and locates within the experimentally accessible fictive temperature range (sensitive MG regime in Fig. 2e) [21]. For MGs with $T_{f}$ remarkably smaller than $T_{f c}$, the relation $T_{f}<T_{f c}$ invariably holds over the entire experimentally accessible $T_{f}$ region, and the materials thus fall into the brittle glass regime (e.g., some Mg- and Fe-based MGs [32, 33], Fig. 2e). For the latter group, the critical cooling rate for embrittlement is lower than that for glass formation. MGs with $T_{f}$ significantly larger than $T_{f c}$ are always tough (e.g., Pt-based MGs [25]) whereas MGs with $T_{f}$ slightly larger than $T_{f c}$ are tough as well in the as-cast state even under different applied cooling rates although they may be sensitive to annealing, as represented in the case of $\mathrm{Zr}_{44} \mathrm{Ti}_{11} \mathrm{Cu}_{10} \mathrm{Ni}_{10} \mathrm{Be}_{25}\left(T_{f c}\right.$ of $\mathrm{Zr}_{44} \mathrm{Ti}_{11} \mathrm{Cu}_{10} \mathrm{Ni}_{10} \mathrm{Be}_{25}$ denoted as $T_{f c(Z r)}$, Fig. 2e) [21]. The precision of our toughness measurements further quantitatively corroborates the critical fictive temperature criterion that describes the different sensitivities of varying MGs' mechanical properties to the cooling rate. This criterion also provides practical insight into toughening some nominally brittle but sensitive MGs through enhancing the experimentally accessible cooling rate during vitrification to access the cooling rate space where $T_{f}>T_{f c}$. 
Mechanistically, plastic deformation of MGs is realized through shear banding and the extent of plasticity or the toughness is a result of competition between shear banding and crack nucleation due to shear induced cavitation $[34,35]$. In order to further understand the distinct cooling rate sensitivities for different MGs, molecular dynamics (MD) simulations have also been employed to probe the atomistic deformation micromechanisms of representatively different MGs (see Supplementary Material). Through inspection of the microscopic cavitation behavior, we found that the cooling rate sensitivity of MGs can be well interpreted within the framework of a cavitation stress fluctuation model [36]. The magnitude of the cavitation stress fluctuation determines the amount of energy dissipation of MGs prior to fracture and a higher cavitation stress fluctuation generally suggests an easier access to cavitation upon loading, and hence a lower toughness. We found that different MGs' cavitation stress fluctuation may demonstrate contrastingly different sensitivities to varying cooling rates during vitrification, which can even trigger a transition in microscopic fracture mechanism and the crack growth trajectory [37]. The combined study of our experimental finding and numerical simulation suggest that the cooling rate, the fictive temperature, and the fracture behavior are interconnected and this relationship can be specific for the MG.

Processing environment, specifically the oxygen content, has been speculated to dramatically vary the critical cooling rate for glass formation and mechanical properties of the resulting MG [38-42]. To simulate the effect of processing environment, we deliberately varied the oxygen content. In addition, other impurities such as tin ( $\mathrm{Sn}$ ) was also considered. For example, among all constitutional elements in $\mathrm{Zr}_{44} \mathrm{Ti}_{11} \mathrm{Cu}_{10} \mathrm{Ni}_{10} \mathrm{Be}_{25}$, commercially available $\mathrm{Zr}$ often contains appreciable amounts of Sn, and hence different contents of Sn lead to different constituent costs. In this study, we prepared three representatively different $\mathrm{Zr}_{44} \mathrm{Ti}_{11} \mathrm{Cu}_{10} \mathrm{Ni}_{10} \mathrm{Be}_{25}$ alloys with 
different chemical purity levels, denoted as A1, A2, A3, respectively (Table 1). Note that A1 alloy was also used for the abovementioned cooling rate effect study. Compared to A1 sample that was alloyed using a relatively higher purity $\mathrm{Zr}$, A2 alloy contains a significantly higher amount of Sn inclusion with a lower purity $\mathrm{Zr}$ which yields a much lower raw material cost. A3 alloy was prepared using a high purity $\mathrm{Zr}$ but under a lower vacuum level and hence contains almost triple contents of oxygen than A1 and A2. The same TPF procedure and water-cooled condition were employed to fabricate SENT toughness test samples for all different alloys. Surprisingly, we found that the dramatic increase of Sn inclusion from $190 \mathrm{ppm}$ to $3000 \mathrm{ppm}$ by $\sim 16$ times plays a negligible role in the toughness of $\mathrm{Zr}_{44} \mathrm{Ti}_{11} \mathrm{Cu}_{10} \mathrm{Ni}_{10} \mathrm{Be}_{25}$. A1 and $\mathrm{A} 2$ essentially demonstrate similar $K_{Q}$ and $R_{p}$ (Fig. 3a and 3b). In contrast, increase of oxygen only by $\sim 3$ times in $\mathrm{A} 3$ alloy can dramatically deteriorate $K_{Q}$ of $\mathrm{Zr}_{44} \mathrm{Ti}_{11} \mathrm{Cu}_{10} \mathrm{Ni}_{10} \mathrm{Be}_{25}$ from $109 \mathrm{MPa}$ $\sqrt{\mathrm{m}}$ (Fig. 3a) to $64 \mathrm{MPa} \sqrt{\mathrm{m}}$ (Fig. 3c), which is accompanied with a decrease in $R_{p}$ as well. Oxygen induced embrittlement has been widely discussed and the formation of oxygencontaining nanoscale precipitates has been suggested as preferential crack nucleation sites [3941]. However, the effect of other metal and metalloid impurities on mechanical properties has been observed with widely ranging consequences [39, 43-45]. Our findings suggest that besides stating nominal composition and cooling conditions, in order to compare and accurately state fracture toughness of MGs, a complete chemical composition profile is necessary. The various effects of impurities on fracture toughness will have a strong economic component. Identifying those impurities that affect fracture toughness negatively will guide the purity requirements which in particular for high purity can be dominant in materials costs.

In summary, we investigated the influence of cooling rate and processing environment on the fracture toughness of two representative MGs via a TPF-based toughness test approach. We 
revealed that their effects can be significant but specific to the alloy. We hypothesize that the cooling rate effect on MGs' fracture toughness can be illustrated within the frameworks of fictive temperature concept and cavitation stress fluctuation model. The effect of impurities on fracture toughness appears less ubiquitous; different impurities can have very different effects on different MGs, suggesting an alloy-impurity specific mechanism. In order to mechanically characterize a MG alloy, not only composition is required but specific cooling rate and a detailed chemical analysis revealing all the impurities are also necessitated.

This work was supported by the Department of Energy through the Office of Basic Energy Sciences (\#DE SC0004889). H.Z. and H.G. acknowledge support from the National Science Foundation through grant CMMI-1161749 and the use of the Extreme Science and Engineering Discovery Environment (XSEDE) under award MSS090046. Experimental helps from William Samela and Michael Power are gratefully acknowledged.

\section{References}

[1] M.E. Launey, R.O. Ritchie, Adv. Mater. 21 (2009) 2103-2110.

[2] R.W.K. Honeycombe, The Plastic Deformation of Metals, Edward Arnold Press, London, 1975.

[3] C.A. Schuh, T.C. Hufnagel, U. Ramamurty, Acta Mater. 55 (2007) 4067-4109.

[4] W.-H. Wang, C. Dong, C. Shek, Mater. Sci. Eng. R 44 (2004) 45-89.

[5] G. Kumar, H.X. Tang, J. Schroers, Nature 457 (2009) 868-872.

[6] J. Schroers, Adv. Mater. 22 (2010) 1566-1597.

[7] J. Schroers, Phys. Today 66 (2013) 32-37.

[8] W. Chen, Z. Liu, J. Schroers, Acta Mater. 62 (2014) 49-57. 
[9] D. Curry, J. Knott, Metal Sci. (2013).

[10] A.G. Evans, E.A. Charles, J. Amer Ceramic Soc. 59 (1976) 371-372.

[11] R. Filip, K. Kubiak, W. Ziaja, J. Sieniawski, J. Mater. Process Technol. 133 (2003) 84-89.

[12] B. Gludovatz, S.E. Naleway, R.O. Ritchie, J.J. Kruzic, Acta Mater. 70 (2014) 198-207.

[13] J. Xu, U. Ramamurty, E. Ma, JOM 62 (2010) 10-18.

[14] M. Launey, R. Busch, J. Kruzic, Scripta Mater. 54 (2006) 483-487.

[15] R.D. Conner, A.J. Rosakis, W.L. Johnson, D.M. Owen, Scripta Mater. 37 (1997) 1373-1378.

[16] K.M. Flores, R.H. Dauskardt, Scripta Mater. 41 (1999) 937-943.

[17] C. Gilbert, V. Schroeder, R. Ritchie, Metall. Mater. Trans. A 30 (1999) 1739-1753.

[18] P. Lowhaphandu, J.J. Lewandowski, Scripta Mater. 38 (1998) 1811-1817.

[19] D. Suh, R.H. Dauskardt, J. Non-cryst. Solids 317 (2003) 181-186.

[20] P.G. Debenedetti, F.H. Stillinger, Nature 410 (2001) 259-267.

[21] G. Kumar, P. Neibecker, L. Yanhui, J. Schroers, Nat. Comm. 4 (2013) 1536.

[22] W. Chen, J. Ketkaew, Z. Liu, R.M.O. Mota, K. O'Brien, C.S. da Silva, J. Schroers, Scripta Mater. 107 (2015) 1-4.

[23] W. Chen, Z. Liu, J. Ketkaew, R.M.O. Mota, S.H. Kim, M. Power, W. Samela, J. Schroers, Acta Mater. 107 (2016) 220-228.

[24] T.L. Anderson, Fracture Mechanics: Fundamentals and Applications, CRC Press, 2005.

[25] G. Kumar, S. Prades-Rodel, A. Blatter, J. Schroers, Scripta Mater. 65 (2011) 585-587.

[26] R. Raghavan, P. Murali, U. Ramamurty, Metall. Mater. Trans. A 39 (2008) 1573-1577.

[27] N. Nishiyama, A. Inoue, Appl. Phys. Lett. 80 (2002) 568.

[28] A. Peker, W.L. Johnson, Appl. Phys. Lett. 63 (1993) 2342-2344.

[29] J. Schroers, W.L. Johnson, R. Busch, Appl. Phys. Lett. 77 (2000) 1158-1160. 
[30] T.A. Waniuk, J. Schroers, W.L. Johnson, Appl. Phys. Lett. 78 (2001) 1213-1215.

[31] J. Ketkaew, Z. Liu, W. Chen, J. Schroers, Phys. Rev. Lett. 115 (2015) 265502.

[32] X. Xi, D. Zhao, M. Pan, W. Wang, Y. Wu, J. Lewandowski, Phys. Rev. Lett. 94 (2005) 125510.

[33] S.F. Guo, J.L .Qiu, P. Yu, S.H. Xie, W. Chen, Appl. Phys. Lett. 105 (2014) 161901.

[34] P. Tandaiya, U. Ramamurty, R. Narasimhan, J. Mech. Phys. Solids. 57 (2009) 1880-1897.

[35] M.D. Demetriou, M.E. Launey, G. Garrett, J.P. Schramm, D.C. Hofmann, W.L. Johnson, R.O. Ritchie, Nat. Mater. 10 (2011) 123-128.

[36] P. Murali, T. Guo, Y. Zhang, R. Narasimhan, Y. Li, H. Gao, Phys. Rev. Lett. 107 (2011) 215501.

[37] R.L. Narayana, P. Tandaiya, G.R. Garrett, M.D. Demetriou, U. Ramamurty, Scripta Mater. $102(2015) 75-78$.

[38] S. Mukherjee, Z. Zhou, J. Schroers, W.L. Johnson, W.K. Rhim, Appl. Phys. Lett. 84 (2004) 5010-5012.

[39] C. Liu, M. Chisholm, M. Miller, Intermetallics 10 (2002) 1105-1112.

[40] S. Madge, T. Wada, D. Louzguine-Luzgin, A. Greer, A. Inoue, Scripta Mater. 61 (2009) $540-543$.

[41] S. Madge, D. Louzguine-Luzgin, J. Lewandowski, A. Greer, Acta Mater. 60 (2012) 48004809.

[42] X. Lin, W. Johnson, W. Rhim, Mater. Trans. 38 (1997) 473-477.

[43] W.H. Wang, Prog. Mater. Sci. 52 (2007) 540-596.

[44] G.R. Garrett, M.D. Demetriou, J. Chen, W.L. Johnson, Appl. Phys. Lett. 101 (2012) 241913.

[45] Q. He, Y.Q. Cheng, E. Ma, J. Xu, Acta Mater. 59 (2011) 202-215. 
Table 1 Three different $\mathrm{Zr}_{44} \mathrm{Ti}_{11} \mathrm{Cu}_{10} \mathrm{Ni}_{10} \mathrm{Be}_{25} \mathrm{MG}$ alloys with different chemical compositions.

\begin{tabular}{|c|c|c|c|c|c|c|c|c|c|c|c|c|c|c|}
\hline Alloy type & $\begin{array}{c}\mathrm{Zr} \\
\text { (balance) }\end{array}$ & $\begin{array}{c}\mathrm{Cu} \\
\text { (wt\%) }\end{array}$ & $\begin{array}{c}\mathrm{Ni} \\
(w t \%)\end{array}$ & $\begin{array}{c}\mathrm{Ti} \\
\text { (wt\%) }\end{array}$ & $\begin{array}{c}\mathrm{Be} \\
(\mathrm{ppm})\end{array}$ & $\begin{array}{c}\mathrm{Zn} \\
(\mathrm{ppm})\end{array}$ & $\begin{array}{c}\mathrm{Cr} \\
(\mathrm{ppm})\end{array}$ & $\begin{array}{c}\mathrm{Si} \\
(\mathrm{ppm})\end{array}$ & $\begin{array}{c}\mathrm{N} \\
(\mathrm{ppm})\end{array}$ & $\begin{array}{c}\mathrm{Fe} \\
(\mathrm{ppm})\end{array}$ & $\begin{array}{c}\mathrm{C} \\
(\mathrm{ppm})\end{array}$ & $\begin{array}{c}\text { Sn } \\
(\mathrm{ppm})\end{array}$ & $\begin{array}{c}\mathrm{O} \\
(\mathrm{ppm})\end{array}$ & $\begin{array}{c}\mathrm{K}_{\mathrm{Q}} \\
\left(\mathrm{MPa} \mathrm{m}^{1 / 2}\right)\end{array}$ \\
\hline & 67.00 & 10.6 & 9.8 & 8.8 & 3.76 & & & & & & & & & \\
\hline $\bar{A} 1$ & 66.83 & 10.77 & 9.75 & 8.73 & 3.75 & $<100$ & 135 & $<100$ & $<20$ & 610 & 220 & 190 & 350 & $109 \pm 3.2$ \\
\hline A2 & 66.4 & 11.1 & 9.6 & 8.8 & 3.9 & $<100$ & 115 & $<100$ & $<20$ & 450 & 130 & 3000 & 320 & $105 \pm 2.8$ \\
\hline A3 & 66.9 & 10.66 & 9.72 & 8.71 & 3.75 & $<100$ & 80 & $<100$ & $<20$ & 330 & 210 & 120 & 860 & $64 \pm 5.3$ \\
\hline
\end{tabular}




\section{Figures}

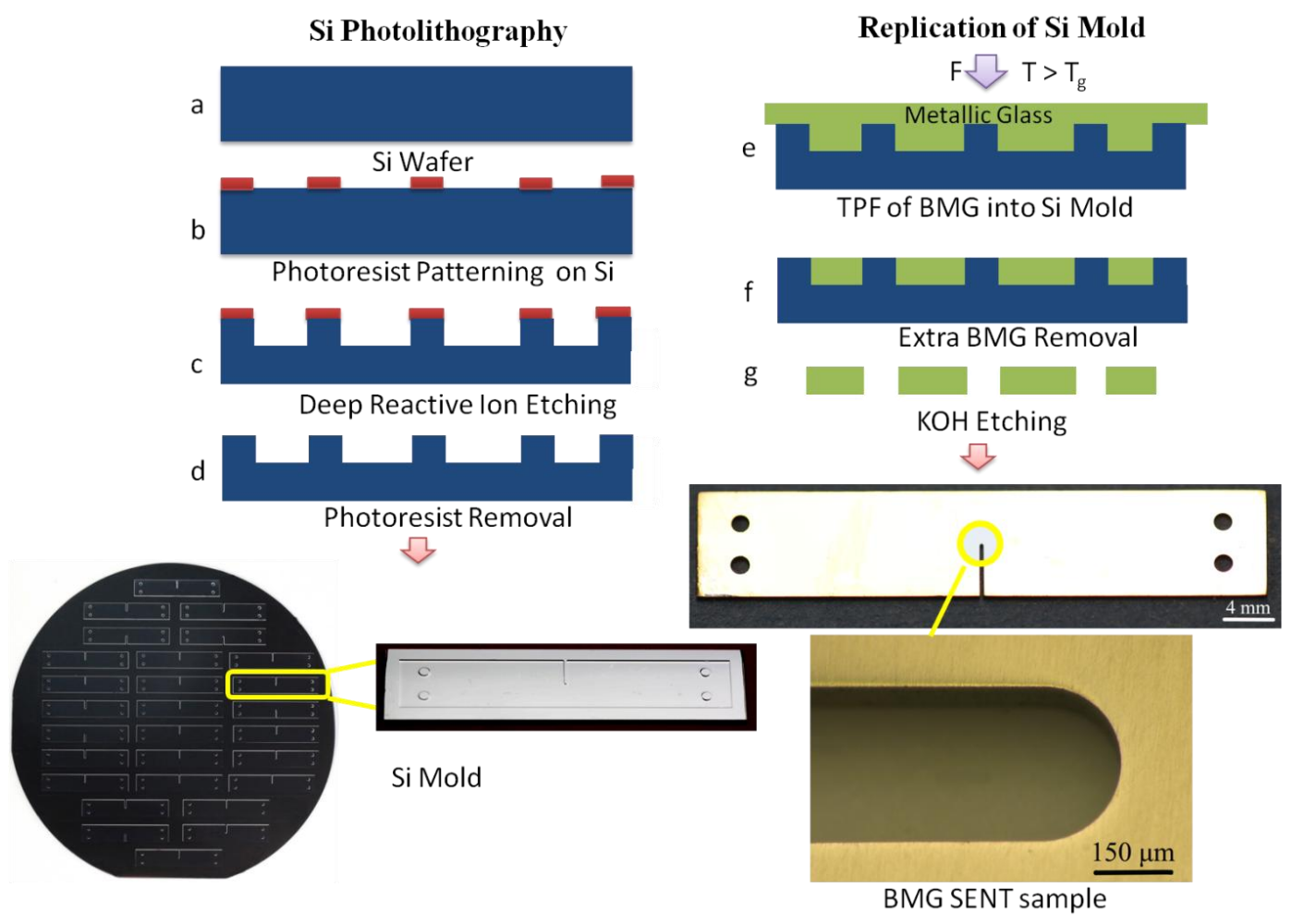

Fig. 1 Schematic illustration of the TPF-based method for fabricating SENT toughness samples. (a) - (d): by Si lithography and deep reactive ion etching, SENT molds with an etching depth of $\sim 350 \mu \mathrm{m}$ are fabricated. (e) - (g): TPF of MGs into SENT molds in the supercooled liquid regime. The extra $\mathrm{MG}$ is removed by careful grinding and the $\mathrm{Si}$ molds are etched by $\mathrm{KOH}$ solution. By using the state-of-the-art Si photolithography, a remarkable notch tip smoothness and precision can be achieved for our fracture toughness test samples. 

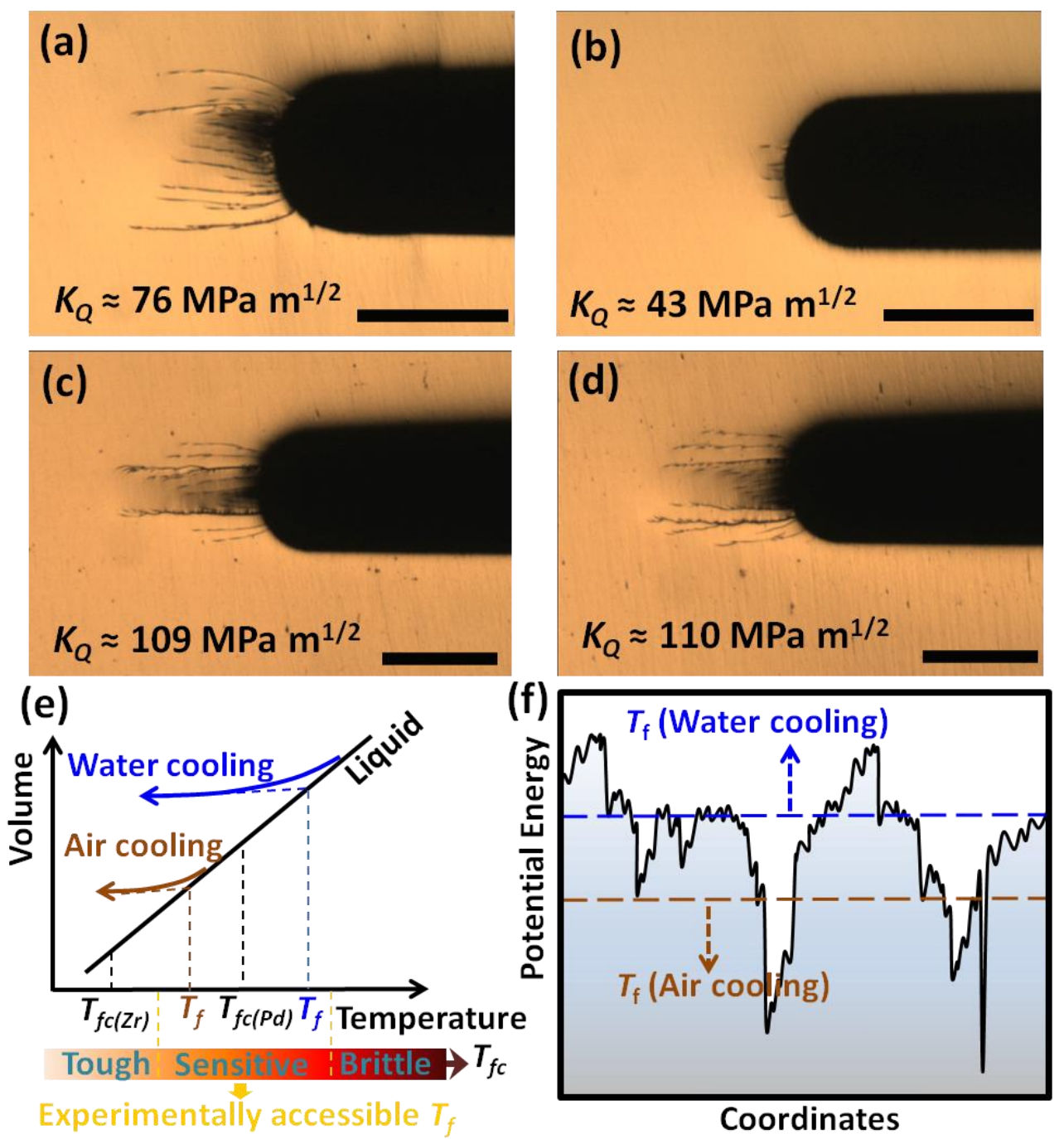

Fig. 2 Different cooling rate sensitivities of $K_{Q}$ for different $M G s$. $\mathrm{Pd}_{43} \mathrm{Cu}_{27} \mathrm{Ni}_{10} \mathrm{P}_{20}$ is dramatically sensitive to the considered cooling rates. $K_{Q}$ decreases from $\sim 76 \mathrm{MPa} \sqrt{\mathrm{m}}$ for the water-cooled sample (a) to $\sim 43 \mathrm{MPa} \sqrt{\mathrm{m}}$ for the air-cooled sample (b), associated with a remarkable decrease in $R_{p}$ from $\sim 255 \mu \mathrm{m}$ (a) to $\sim 30 \mu \mathrm{m}$ (b). In contrast, $K_{Q}$ and $R_{p}$ of $\mathrm{Zr}_{44} \mathrm{Ti}_{11} \mathrm{Cu}_{10} \mathrm{Ni}_{10} \mathrm{Be}_{25}$ are almost insensitive and unaffected by varying the cooling rate from water cooling (c) to air cooling (d), although they may be sensitive to annealing. The different sensitivities of MGs' fracture toughness to cooling rate can be rationalized within the framework of fictive temperature concept (e) and (f). Scale bar: $300 \mu \mathrm{m}$. 

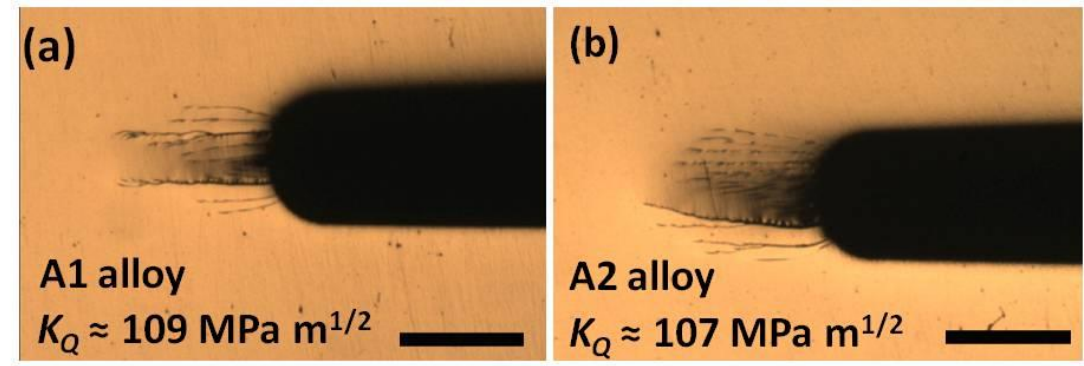

(c)

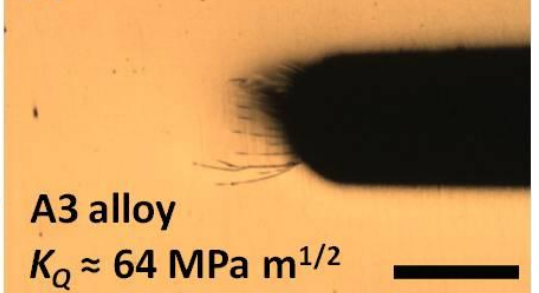

Fig. $3 K_{Q}$ of $\mathrm{Zr}_{44} \mathrm{Ti}_{11} \mathrm{Cu}_{10} \mathrm{Ni}_{10} \mathrm{Be}_{25}$ shows different sensitivities to different chemical impurities. A remarkable increase of Sn impurity from Al alloy (a) to A2 alloy (b) by 16 times does not clearly degrade $K_{Q}$, while an increases of oxygen impurity only by $\sim 3$ times significantly deteriorate $K_{Q}$ from $\sim 109 \mathrm{MPa} \sqrt{\mathrm{m}}$ (a) to $\sim 64 \mathrm{MPa} \sqrt{\mathrm{m}}$ (c), associated with a dramatic decrease in $R p$. Scale bar: $300 \mu \mathrm{m}$. 


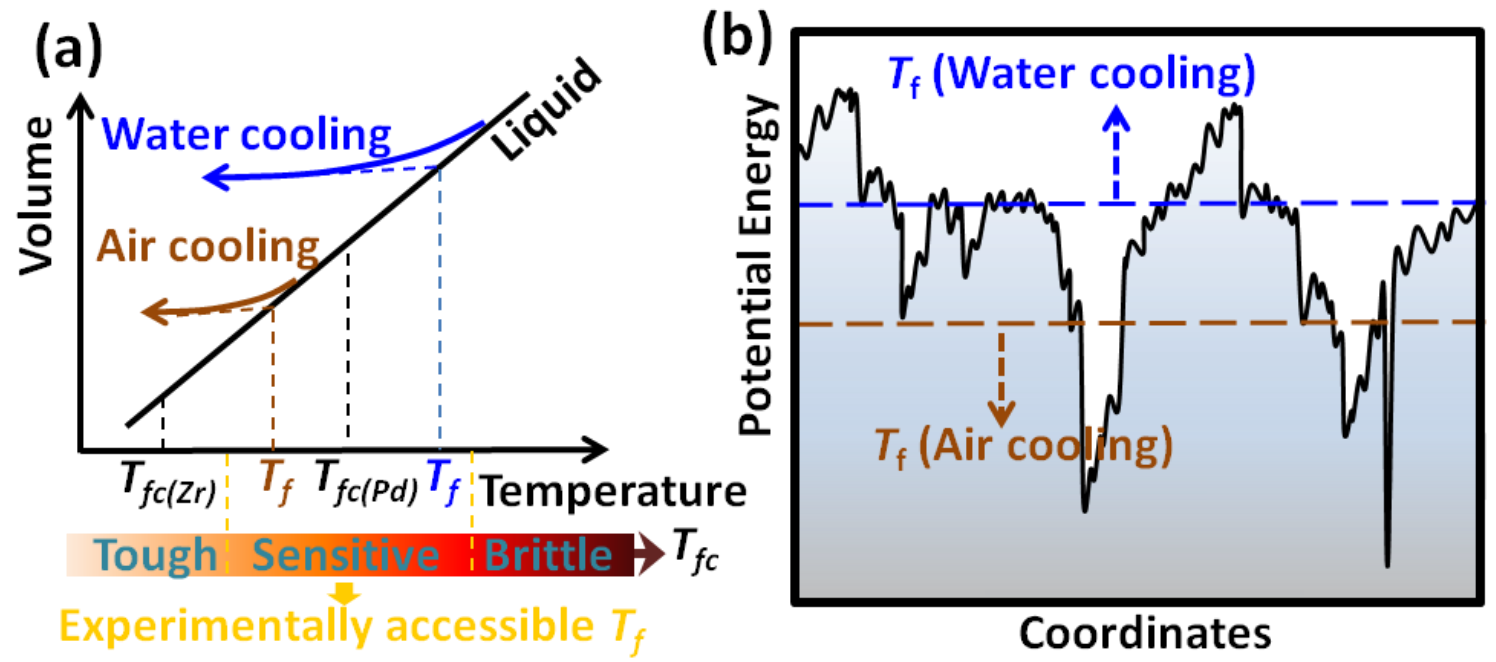

